\title{
Editorial: The key drivers of change in UK pensions
}

When the late Chou En-Lai, then premier of the People's Republic of China, attended a banquet in his honour in Paris, he was asked by the French president for his views on whether the French Revolution had been a good thing. He replied that, from a Chinese perspective, it was still too early to say.

We do not all necessarily share Chou's implied definition of the long term in his assessment of change, but it is instructive for all of us to stand back from the dust and clamour of short-term events in the world of retirement provision in the UK, and to take a longer view. There is a great danger today that anxieties about current circumstances may override reason and principle in determining the financial wellbeing of future generations of pensioners. Stock market retreats, the disappearance of fund surpluses, increasingly complex regulation, and a growing hysteria in the press are threatening to cause serious damage to the system in the absence of a clear direction to public policy. Changes driven by short-term considerations are likely not to lie in the nation's best interests.

It is therefore worth considering what influences are driving changes in pensions provision, and whether the changes are beneficial. If not, then perhaps we need to reconsider whether our current response to these influences is the right one. Words like 'beneficial' and 'right' require a context, and in the case of pensions we can do no better than take
John Stuart Mill's definition of utilitarianism: 'that which is for the greatest good of the greatest number.'

Before turning to three important areas of change within pensions, it is worth commenting on the 'dust and clamour' that is obsessing certain sections of the media. It is important to recognise that current market conditions, though depressing, are not a sound basis for setting out matters of principle. It is easy to see some of the sources of confusion.

\section{'The world will end'}

There is a growing sense that the traditional approaches and structures no longer work. Over the past two decades we have seen, first in the USA and subsequently in the UK and other countries, a rise in the popularity of defined contribution (DC) plans. These have begun to replace the more traditional defined benefit (DB) arrangements, typified in the UK by the final salary scheme, in which the pension is based on the employee's salary at the time of retirement. Recent figures from the National Association of Pension Funds (NAPF) indicate that over $80 \mathrm{UK}$ DB plans were closed to new members in 2002 alone, ${ }^{1}$ and in some cases even closed to future service for existing members. In most cases these decisions have been driven by the increasing cost of the scheme, which appears unamenable to control; some companies 
have concluded that the 'nuclear option' is all that remains to them.

One might well ask how we arrived at this point, from the time in the mid-1990s when many people felt that the successful UK second pillar was a model for other countries. It is clear with hindsight, however, that the seeds of today's plight were already in the ground and growing fast.

It may be that there was some complacency following a long period of rising stock markets, leading to large reported surpluses and hence to contribution holidays. Many companies set in motion plans to recapture the 'surplus' that has now been revealed as, in effect, an estimation error. More seriously, benefits were often extended to a level that then looked affordable but is now revealed to be unsustainable. Early retirement programmes were often paid for by pension funds: one might reasonably speculate that those who retired in the 1990s took rather more than their generation's fair share out of the pension pot.

Meantime there were other developments. The maturescence of pension funds, and their consequent greater size in relation to the net worth of their sponsoring company, served to reduce the employer's room for manoeuvre. The largely illogical minimum funding requirement introduced in the Pensions Act 1995 drove investment policy in the wrong direction, forcing funds to crowd into the gilt market at a time of sharply decreasing supply. Finally, the removal of dividend tax exemption has reduced the funds' income from equities. Contemplating the future, the circumstances of today appear very unforgiving, but some of the issues, such as stock market values today, are less important than they currently seem. We need to look at the long term.

\section{It's the liabilities that are wrong}

I have not mentioned recent stock market performance as a cause of change. Clearly, there are people reacting strongly to it. In a more fundamental sense, however, the markets have just done what markets do: every pension fund's strategic planning process or asset-liability modelling should have allowed the possibility of what has just happened. I do not say that they should have forecast the market declines, or even considered them likely. But the modellers should have thought them possible, and actively looked at the consequences to the fund if they occurred.

Most asset liability management (ALM) exercises would embody an assumption that equities would provide a long-term return roughly 6 per cent over inflation, with volatility in the region of $15-20$ per cent. That statement was true at the end of the 1980 s, and has not varied since. ${ }^{2}$ From the end of 1990 to the end of 2002, that is almost precisely what the equity market did. The total return of the FTSE All-Share was 9.5 per cent per annum for the 12 years to December 2002, while retail price inflation averaged 3.5 per cent per annum. Annual volatility was 16.6 per cent. Though the identity of outcome with reasonable assumption is coincidence, it is illustrative that if in December 1990 we had been guaranteed a FTSE 100 close just below 4,000 in December 2002, most investors would have been happy to hold equities over the period. It would be quite reasonable to maintain that 6 per cent real return expectation for the long-term future. ${ }^{3}$ It was considered in the past a fair basis for investing in stocks, and it remains so today. The nature of the markets has not changed. Equities are still to be expected to outperform bonds in the long term, by about 3 per cent or so. They are still a natural investment for most pension funds, not because of an expectation that they 
will rapidly recover 1999 levels, but because the 3 per cent equity risk premium is critical to sustain the contribution and benefit levels that our system relies on.

Equities are not really the problem. Bonds are. The key problem for most funds is the extraordinarily high value of the liabilities in an environment of low long bond yields and a flat yield curve. It is not reasonable to expect pension finances to improve dramatically over the next few years from high equity returns of the type we saw in the 1990s. It is reasonable, on the other hand, to expect them to improve considerably with the resumption of a normal upward-sloping yield curve, lowering the value of liabilities (on the assumption that a steepening curve is achieved by higher long bond yields). Now that public finances require a large amount of new debt issuance, there may be grounds for optimism for pension funds in higher yields and possibly a little more inflation.

\section{Three areas of change}

\section{DB versus DC}

The case can easily be advanced that DC is better than $\mathrm{DB}$ for people who do not remain with one employer their entire working life. It avoids unfair subsidy, and preserves portability. It also allows the employee a greater measure of individual control over investment policy, which is to say over risk policy. And of course in principle a pound invested in a DC plan will earn the same return as a pound in a DB scheme, given the same investment policy and equal efficiency in the implementation of it.

The main force impelling the growth of DC in the UK is cost. If the cost of a DB scheme is excessive because of 'benefit creep', the employer's only escape is to close the fund, and set up a new one. To avoid a repetition of the cost problem, a DC plan is very attractive. As the Myners Review ${ }^{4}$ commented, however, the average contribution level in UK DC plans is substantially below the level required to provide a pension approaching the traditional two-thirds of final salary.

In terms of efficiency as a wealth generator, DC lags behind. In practice, the DC pound has a more conservative investment policy, leading to lower long-term returns. It also faces higher charges, because of the individual record-keeping and reporting. Finally, since contributions are lower to begin with, the DC pound is really only perhaps 50 pence (the NAPF annual survey in 2002 reported that average DC contributions were 6 per cent, compared with 12 per cent in $\mathrm{DB})$. In recognition of the individual advantages it offers, and the costs embedded in providing those, a DC contribution needs to be higher in order to provide the same pension.

DC implemented properly can work well, and deliver the advantages that are noted above. But if it is simply regarded and treated as a low-cost alternative it will not provide proper pensions.

DB is crude when it comes to individual fairness, but as a collective instrument it is a most efficient engine for long-term wealth creation. Figure 1 shows a representation of how wealth is accumulated and disbursed in respect of one notional individual within a DB scheme, from initial membership to post-retirement death. ${ }^{5}$ The bars above the zero line show the contributions and investment returns respectively as monetary quantities. The bars below the line show the pensions paid out. There are two features of the process that often cause surprise. These are, first, that about 80 per cent of the wealth accumulated arises from returns, and only 20 per cent from contributions; and, secondly, that 


\section{Sources and applications of funds}

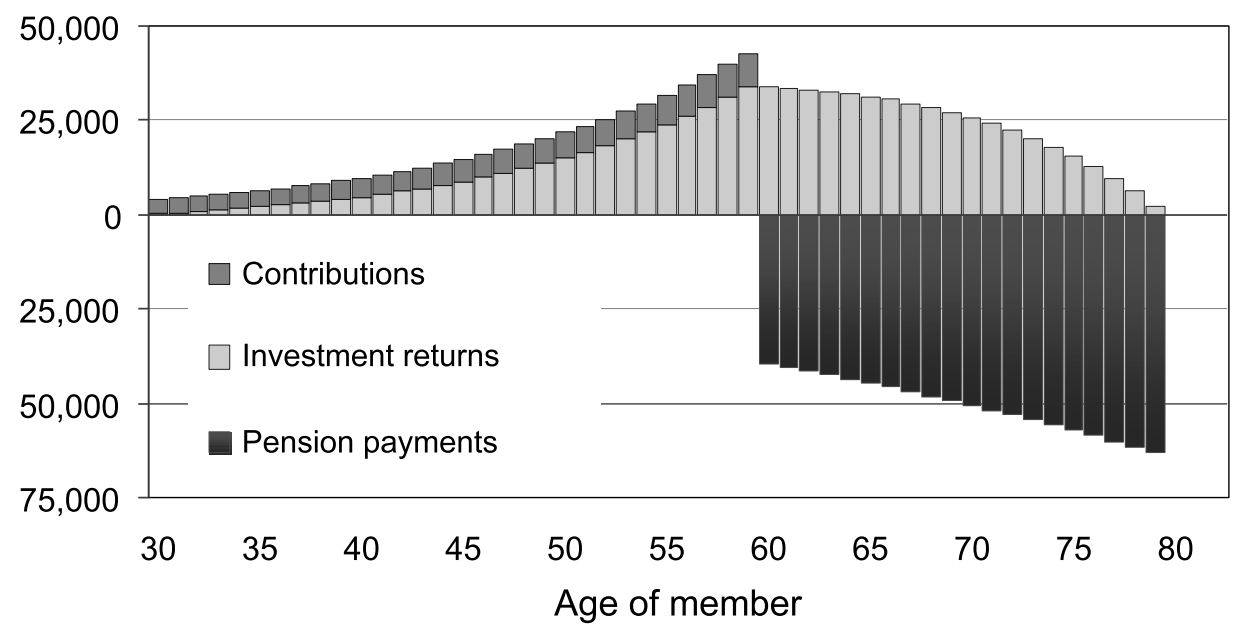

Figure 1: The efficient wealth engine

most of the investment returns are earned in the period after retirement. Both are substantial advantages of DB over DC. From the first, we can infer that the DC pot will already be smaller at retirement, because of greater structural cost drag on the investment performance. From the second, we can infer that the smaller pot will earn lower returns after retirement, because as an individual account it will go largely, if not wholly, into a bond-type exposure. The post-retirement DB policy retains its equity allocation, however, because the DB scheme diversifies not only across individuals but also across age cohorts. It can thus tolerate a degree of market risk that the solitary individual can not.

The recent Pickering Report ${ }^{6}$ contains a number of proposals for relieving the worst of the burdens on employers with DB plans, such as the inability to vary benefits once granted, and the complexity of the tax regime. These proposals, if they are accepted, are unlikely to reverse the shifts that have already been made away from DB, but they may slow the momentum of what has threatened to become a stampede.
DC and DB both have their own advantages. One is fairer, the other is more efficient. It would be a huge loss in economic terms if we lost the efficient wealth-accumulation vehicle that is DB, but that threat is still present.

\section{Constitution, governance and regulation}

The past decade has seen the Goode Committee, ${ }^{7}$ which reported in the aftermath of the Maxwell affair, and the Myners Review, set up to identify barriers to prudent and efficient investment and to propose ways of eliminating them. Most recently the Pickering Committee, which has proposed simplification of legislation, regulation and tax for pension funds, along with some measures to allow reasonable reductions in future benefits for funds whose only other choice is closure or winding up.

In terms of fund governance, the Goode Committee was followed by the Pensions Act 1995, which introduced some good ideas, and one exceedingly bad one. The good ideas included the 
Statement of Investment Principles, though in practice it met with varying success according to the inclination of each fund's trustees. In some cases it became a guiding document for the stewardship of the fund, and a framework for benchmarking the trustees' own performance. In other cases, it was as brief and as vague a document as minimally to comply with the law, created as a chore, and filed and forgotten.

The bad idea was the minimum funding requirement (MFR). It defined UK equities as the risk-free asset in relation to UK active liabilities, unencumbered by any evidence in favour of this proposition. It identified the 15-year conventional gilt yield as the equivalent basis for retired liabilities, which was not absurd, but as a practical matter its effect was to send half a trillion pounds of pension assets off in dogged pursuit of a much smaller investible bond population that was already being culled through public sector debt repayment. The MFR discouraged equity diversification outside the UK market, and compelled many pension funds to overpay to gain access to the 15-year yield at a time when the government was retiring debt hand over fist. The legacy of that remains with us today, with the gilt yield curve over ten years severely distorted by this artificial demand. At long last, however, MFR is on the way out, censured by Myners and unloved by many.

If there is a silver lining, it is that the abolition of MFR is as positive for pension funds as was the removal of exchange controls 23 years ago.

The Myners Review delivered a cogent critique of institutional investment in the UK, and enunciated a set of principles that ought to be followed in the stewardship of pension funds. It identified several weaknesses in current practice, and some practical solutions. In many cases these were already practised by the best run UK funds: efficient decision making, appropriate delegation, the use of expert advice and clear and relevant reporting were among those. In other cases, such as the payment of trustees and the control and monitoring of transactions costs, Myners went beyond current practice. All in all, the recommendations were consistent with prudence and efficiency.

Nonetheless, it appears anecdotally that many trustees and companies regard compliance with Myners as burdensome, and it does raise the issue of whether there are too many UK pension funds too small to be run to the highest standards. If this is true, then (as Pickering points out) the solution may be along the lines of fund organisation in the Netherlands, where large companies run their own funds, while smaller employers participate in industry-wide collective plans. In this way, all funds are large enough to sustain the professional resources necessary to conform with best practice. Pickering noted that this is an area where current legislative complexity militates against the efficient solution, and has proposed changes.

Taken together, Myners's codifying of best standards in governance, and Pickering's proposals for a simplified legislative and regulatory regime to make the best standards more readily feasible, offer a good deal of hope for the future. Unusually for the UK, both these bodies took the time to examine how other countries conduct these affairs. It is late in the day for occupational pensions, but better late than never.

\section{Investment management - Three choices}

The UK pension fund community has moved a considerable way from the traditional model of single or multiple balanced management, with a target 


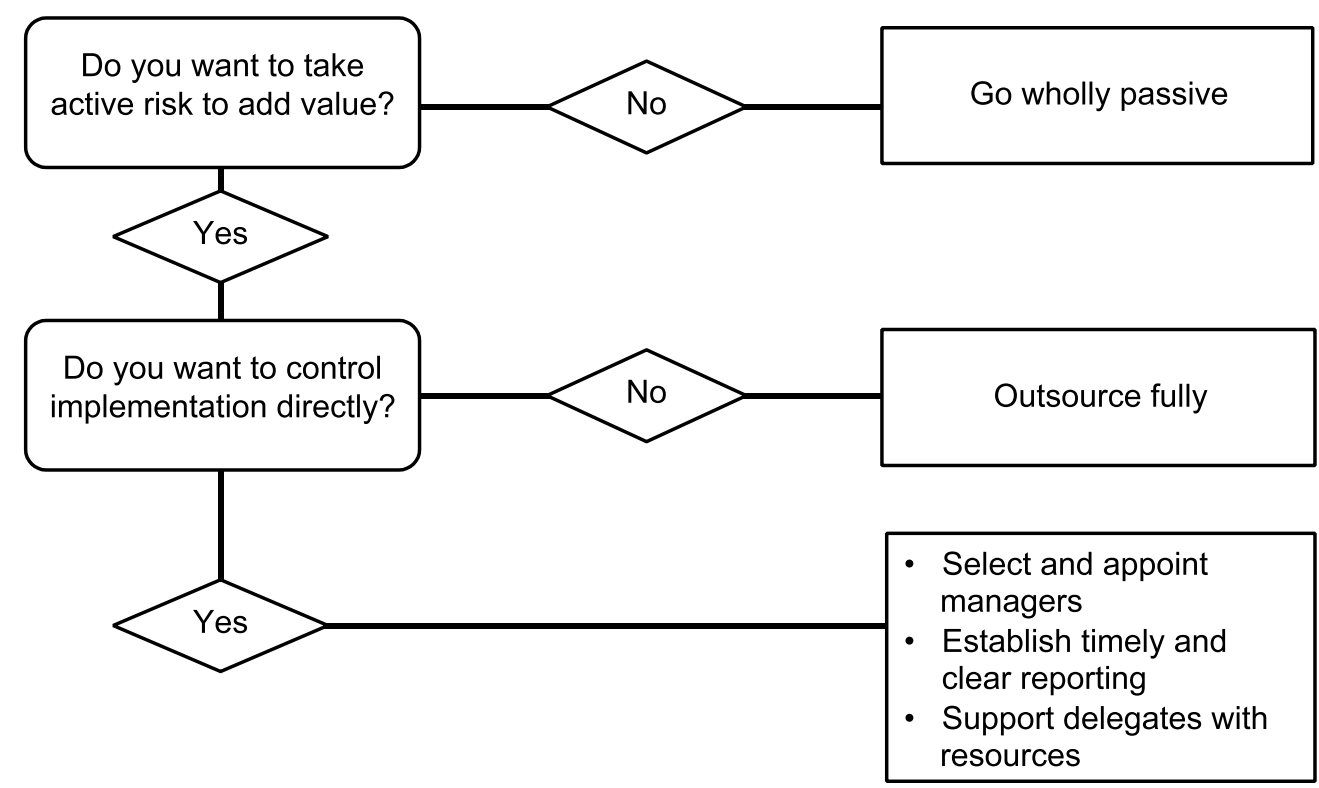

Figure 2: Choices in implementation

related to the average achievement of all other funds. Trustees and companies have become more critical in appraising investment management as they would any corporate activity, and have begun to question the solutions offered. One size no longer fits all. Investment management is now widely accepted to be the implementation of the investment strategy, and as with any other economic activity the optimal form of implementation can vary with circumstances and corporate culture.

Figure 2 sets out a simple representation of the key decisions in implementation, and their consequent implications. The first question is about risk, and specifically the risk of active management. In recent years many funds have answered the question negatively, largely as a result of disappointment in their active managers' performance, and it is estimated that up to 30 per cent $^{8}$ of UK pension assets are now managed passively. Passive management is a rational decision for the disillusioned, and also the most robust default for those who have no convincing method of selecting superior managers.

For those who have such conviction (or access to it) active management offers an attractive proposition. A fund with 60 per cent in equities and 40 per cent in bonds can expect a return of roughly 7 per cent on Russell's current capital market assumptions (equities 8.2 per cent; bonds 5.2 per cent). If 1 per cent can be added through active management, that represents the same prospective return as a passively managed fund with 90 per cent in equities and 10 per cent in bonds, but with a level of fund risk consistent with the 60/40 mix. The question then is the degree of direct control and involvement in the implementation process.

Those who wish to outsource fully might in the past have hired a single balanced manager, but this is hard to reconcile with the principle of outsourcing since it requires in-house expertise to select and monitor the manager. In recent years a more realistic outsourcing solution has become available in the form of multi-manager 
funds, where the service provider is a manager of managers with the ability to select and replace managers without breaking step, as it were. The increasing popularity of this approach is evidenced by the number of such providers in the past few years.

The remaining choice is that still chosen by the majority of large funds, with the resources and economies of scale to construct custom multi-manager solutions, normally with the advice of an investment consulting firm specialising in investment manager research. Even for such funds, the outsourced solution will be attractive in the more marginal investments such as private equity, hedge funds and property.

As the standards of best practice become clearer and the resource requirement for direct management becomes better understood, we may expect a number of funds to abandon the third group and move to passive management or outsourced active management. Since most of those inclined to go passive have already made that choice, the outsourcing solution promises to see considerable expansion in the coming years.

\section{Conclusion}

We are where we are, though that does not make it less painful. Nevertheless, there are some grounds for optimism. Bond market constipation cannot last for ever, any more than the stock market bubble could. As markets move on, the short-term instincts will give way to a better understanding of investment and risk. Over the coming years, ALM studies will be reviewed with a much higher quality of understanding than many were accorded in the past.

The Myners and Pickering reports bring respectively a new standard of professionalism to pension funds, and a new clarity to legislation and regulation, if the latter is implemented. It is important that the corporate sector has more encouragement from the state to continue providing good occupational pensions, and it is particularly critical that there is clear recognition in public policy that the DB structure has a large role to play in delivering pensions efficiently and economically.

Lastly, investment management, the implementation step, is undergoing its own revolution, as more emphasis is put on eliminating leakage and loss from the levels of prospective return we all now more realistically confront. When we look at equity returns of 8 per cent as the average, excessive costs and underperformance are less easily tolerated. Myners's 'prudent expert' will begin to exert discipline throughout the process; accountability will have a very sharp edge indeed.

But our pensioners deserve nothing less.

\section{References}

1 National Association of Pension Funds (2002), '28th Annual Survey', London.

2 Hensel, C. R. and Turner, A. L. (1992) 'Making superior asset allocation decisions: Implications of recent research commentaries', Russell Research Commentary, Tacoma.

3 Russell's capital markets assumptions (expected returns) as at 30th September, 2002 were UK equities 7.4 per cent; UK Government fixed interest 4.4 per cent; UK cash 3.6 per cent and UK inflation 2.4 per cent.

4 Myners, P. (2001) 'Institutional investment in the United Kingdom', HM Treasury, London.

5 This is a simplified model of wealth accumulation and disbursement, assuming 2.5 per cent inflation, 3 per cent salary increases, 5 per cent bond return and 8 per cent equity return; the portfolio is 60 per cent equities and 40 per cent bonds; and the pension begins at two-thirds of the 
average of the last five years' salary. I am indebted to my colleague Don Ezra for this form of representation. (See Ezra, D. D. (1989) 'A Model of Pension Fund Growth', Russell Research Commentary, Tacoma.)

6 Pickering, A. (2002) 'A simpler way to better pensions', independent report, The Stationery Office.

7 Goode, R. (1993) 'Pension Law Reform', HMSO, London.

8 Maclaren, A. (ed.) (2002) 'UBS Pension Fund Indicators, 2002, A long-term perspective on pension fund investment', UBS, London. 